\begin{tabular}{c|c}
\multirow{2}{*}{ EESD'15 } & The $7^{\text {th }}$ International Conference on Engineering Education for Sustainable Development \\
\cline { 2 - 2 } & Vancouver, Canada, June 9 to 12, 2015
\end{tabular}

\title{
SUSTAINABLE DEVELOPMENT FOR ENGINEERS THROUGH A THEMATIC RESTRUCTURING OF EXPERIENTIAL LEARNING
}

\author{
Paul M. Winkelman ${ }^{1,2}$, Jason Penner ${ }^{1}$ and Ara Beittoei ${ }^{1}$ \\ ${ }^{1}$ University of British Columbia, Canada \\ 2 pwinkel@mech.ubc.ca
}

\begin{abstract}
Complex engineering projects often require interdisciplinary approaches and the ability to understand and navigate professional, cultural, social, and political contexts in order to find sustainable solutions. Piloted in 2011, the Faculty of Applied Science at the University of British Columbia offers APSC 461 and 462, Global Engineering Leadership, to better prepare graduates for a broader scope of engineering practice. The courses emphasize four key themes: leadership, ethical community engagement, participatory planning and understanding differences. These four themes provide a strong framework for student learning as they are intended to problematize the technical mindset of traditional engineering practice (e.g. linear and hierarchical thinking; a western, scientific worldview). In APSC 461, drawing on a pedagogy of Community-based Experiential Learning (CBEL), the four themes are explored through a series of talks (guest speakers, instructor), student-led discussions and workshops, and collaboration on a community project proposed by a local organization. Students further engage in the concepts through written reading responses and reflections. The preparation provided by the four themes becomes even more important for those who continue in the international service learning course module of APSC 462. This practicum is hosted by an agro-ecology centre in a rural community in Mexico. Anecdotal evidence suggests these themes support critical reflection and student preparedness to work with community partners. More formalized studies are required to properly assess the impact which will, in turn, inform future development of the courses.
\end{abstract}

\section{INTRODUCTION}

The world is becoming increasingly interconnected with growing concerns around complex problems like climate change, inequality, planetary boundaries, and international development (Kates et al., 2001). These challenges often require interdisciplinary approaches and the ability to understand and navigate professional, cultural, social, and political contexts in order to find sustainable solutions (Wiek, 2011). The role an engineer can have in such approaches necessitates a response from engineering education to address the non-technical requirements of engineers. Recent research into engineering education calls for preparing engineering students that can be better leaders and ethical practitioners of the future (National Academy, 2005). Today's engineers can bring their expertise to a broader range of issues than traditionally considered. They are playing more significant roles in local communities and international communities, health, social and environmental issues (Lima and Oakes, 2006). However, engineering education typically focuses on providing graduates with technical knowledge and skills. There has been a disengagement between public-welfare and social justice issues and technical work in engineering courses. However, understanding the impacts of science and engineering on public welfare and social justice issues itself is a core professional skill (Cech, 2014). In order to be able to develop students' knowledge, skills, and attitudes such that they are prepared to address these non-technical challenges, new pedagogies need to be employed covering a wider range of topics. 
Based on the conviction that engineers are often called upon to take on leadership roles facing the challenges of global sustainability, the Faculty of Applied Science at the University of British Columbia introduced APSC 461 and APSC 462, Global Engineering Leadership in 2011. Building on the core value of service in leadership, the course learning objectives explore the roles of the engineer in a wide range of situations, social and cultural contexts, and levels of responsibility. Key concepts in leadership theory are identified and opportunities are presented for students to develop critical thinking. In addition, the courses seek to equip students with many of the graduate attributes as stipulated by the Canadian Engineering Accreditation Board $(C E A B, 2014)$ such as communication; professionalism; impact of engineering on society and the environment; ethics and equity; and lifelong learning (Croft, et al., 2013). An important goal of the course is to provide students with experiences and education to develop and hone these knowledge and skills while enhancing the service ethic within their professional development. Finally, the courses seek to deepen the students' understanding of the interconnected nature of global challenges and develop within them a passion for leadership through service. These challenges are presented against a backdrop of sustainable development.

APSC 461 (formerly MECH 410E) is an on-campus course structured around guest lectures, tutorial discussions, readings, reflections and community based experiential learning projects. APSC 462 (formerly MECH 410P) is its optional, follow-up practicum where students continue their learning through International Service Learning (ISL) placements (to date, these placement have all been in Mexico).

At the core of APSC 461 are the pedagogical practices of community-based experiential learning (CBEL) (Centre for Community Engaged Learning, 2015). Students collaborate on a project proposed by a community organization. Several principles that inform the course draw on key technical elements of service learning: engagement, reciprocity, integration with course content and critical reflection. Service learning involves working with and being introspective about what is happening in those moments of being in relationship with another, most often relationships between student and community. In order to justify service learning as a 'legitimate' practice in academics, linkages must be made to theoretical/conceptual components (Kronick, et al., 2011). Thus, APSC 461 course projects include a research component and expand on traditional service learning to include research as service (Goss, et al., 2010).

CBEL became the impetus for the thematic restructuring of the course. Anecdotal evidence from both community partners and students made it clear that students could be better prepared to undertake community projects for they had struggled with particular aspects foundational to community engaged projects. To improve student preparation, we generated three CBEL-inspired themes: ethical community engagement, participatory planning and understanding across differences. Together with the central concept of leadership, these became the four key themes of Global Engineering Leadership.

If these themes are to disrupt the traditional engineering mindset, we first need some insights into what that mindset might be, how it might be otherwise and what might be gained from other perspectives. To begin the exploration, we chose to explore the engineering concepts of "technical" and "non-technical".

\section{THE TECHNICAL/NON-TECHNICAL DICHOTOMY}

The technical/non-technical dichotomy is commonly used within engineering. The Canadian Engineering Accreditation Board (2014), for example, states that the engineering program should be "designed to assure ...an exposure to non-technical subjects that supplement the technical aspects" (p. 16); "exposure" suggests that the study of the subject matter is limited, and "supplement" speaks of something not central to engineering itself, but perhaps something that provides a bridge to the non-engineering world.

Engineering is thus divided into two worlds on unequal footings. Faulkner (2000) provides an example of this in her study of software developers. A computer program is generally divided into two parts, the technical and the non-technical. The technical part performs the main function of the program and is known as the "meat"; the non-technical part consists of the user interface and is know as the "fluff". Faulkner adds that these two are often viewed as being mutually exclusive: if one is "good at" or has a passion for one side of the divide, one cannot be "good at" or have a passion for the other side. As 
"mutual exclusivity" presupposes a dichotomy, the dichotomy itself merits a closer look. Faulkner (2000) maintains that the very use of dichotomies is a manifestation of technical bias.

Its limitations notwithstanding, the technical/non-technical dichotomy provides fertile ground for course development as it begins in familiar engineering territory. The first task is to deconstruct the traditional dichotomy. Faulkner's (2000) "meat"/"fluff" distinction speaks of a value system and this will form the basis of the deconstruction. We begin by exploring possible meanings of "technical" as suggested by engineering usage, exposing underlying values. We then compare these values with those of the four proposed course themes with the goal of understanding their theoretical and pedagogical implications.

\section{1 “Technical” as Used in Engineering}

Technical drawing has been a mainstay of engineering programs for many years. Like many of its analytical cousins, it relies on mathematics for its legitimation: the drawing is done using standard geometric shapes and the standard views (e.g., front, top, isometric) assume a Cartesian coordinate system. As the number of basic shapes and standard views are few in number engineering students are expected to "see" the same object and produce the same drawing of that object. The "technical" therefore demands a high degree of conformity. As these drawings are typically used to manufacture parts, they become a communicative device, and "technical" also carries the sense of the unambiguous with all extraneous information removed (for instance, redundant dimensioning is considered "wrong"). With ambiguity removed, meaning is reconfigured as property, independent of context.

Conformity, as implied by the "technical", takes many forms within engineering. The "right answer" mindset is perhaps its most obvious manifestation, strongly supported by the mathematical concepts and models which form the backbone for most, if not all, the more traditional engineering courses. Thomas Kuhn (1970) offers some insight in this regard as he distinguishes between puzzles and problems. Puzzles are like problems in that there are multiple paths from the starting point to solution, but differ in that puzzles imply a single, correct solution.

Conformity also takes some more subtle forms. Consider, for instance, the term "practical". Engineers often think of themselves as those who are concerned with the "practical application" of science and mathematics. Being neither scientists nor mathematicians, engineers must therefore distinguish themselves, at least in part, with respect to the "practical". But what does it mean to be "practical"?

To be practical, one must presumably have an established practice to draw on. As a practice speaks of repeatability, it must find its application in a reasonably wide spectrum of engineering situations. A practice is valued as it provides a direct path from problem to solution, favouring "linear thinking".

What allows an engineering solution or approach to be "practical"? Weinberg notes that "[p]ower creates practicality" (p. 8). This comment was made in the context of slavery and shows how ethical questions can be side-stepped and reconfigured as "practical" in the framework of a dominant political and economic system. Hence, as engineers follow the practical, they tend to uphold the political system and the power it maintains. The widespread use of the term "practical" implies that, like the electricity they learn about in class, engineers are to follow the path of least resistance.

Political structures which maintain power are normally conceived of as being hierarchical. As engineers typically work in hierarchical structures (Nieusma and Blue, 2012), engineering students expect this to be part of their future. Their educational program does little to challenge this assumed structure. The engineering program resembles a hierarchy as science and mathematics are presented as being "foundational" to engineering, providing prerequisites for "upper" level courses. Science itself uses hierarchies because, in the words of Herbert Simon, "nature loves hierarchies" (Mirowski, 2002, p. 465). Simon has also had direct impacts on engineering through the his ideas of the "ill-structured problem" and the "sciences of the artificial", promoting hierarchies to facilitate problem-solving.

Conformity can also be maintained through shaming, as can be seen in Faulkner's (2000) software developers who took great pride in their technical prowess and ridiculed the lack of such prowess in 
others. Ridicule is a form of shaming. Its power lies in he fact that shaming, unlike guilt, cannot be forgiven; there is no redemption (Visser, 2002).

The technical is often presented as that which is not social. Nieusma and Blue (2012), for example, speak of engineering practice which "neatly separates out the 'technical core' from the 'social context'" ( $p$. 53). Faulkner (2000) speaks of the "social vs technical" (p. 759). One of the participants of her study speaks of humans as having emotions and feelings which can, unlike machines, be hurt; it is therefore preferable to work with machines. Machines, the participant reasoned, can be controlled, whereas people cannot be; engineers are taught to concentrate on that which can be controlled. As engineers move into sustainability, this mindset downplays the social in favour of the environmental, as the latter is more controllable.

\section{DEVELOPMENT OF KEY COURSE THEMES}

Sustainable development sets the backdrop for both course content and project work with local and international community organizations. The four key themes were created to provide partial grounding for the values implicit in sustainable development, serving to focus students' attention on the social, and better prepare them for CBEL. We explore each theme below, and the values they promote, from the perspective of the technical mindset (if possible) and from that of the "non-technical", (sustainabledevelopment oriented) mindset. In so doing, we hope to show how these themes are mutually supportive as they facilitate a shift in thinking. Finally, we discuss the pedagogical implications of this shift.

\subsection{Leadership}

The hierarchical structures employed in engineering, both within the construction of the students' knowledge and in the institutional structures at their places of study and work, suggest a particular kind of leadership where the leader is at the "top" of a pyramidal structure wielding some kind of power to those below who essentially do the leader's bidding. The "right answer" mentality demands that there be some centralized authority against which the validity of answers can be measured. Authority and knowledge (truth) tend to coalesce. This view of leadership affects how engineers see themselves as both leaders and "subjects" of the leaders.

APSC 461 encourages looking at leadership more from the perspective of "servant-leadership" (Spears, 2004). The idea is to deliberately move away from autocratic, hierarchical styles with a much stronger focus on community, caring and personal growth. Spears identifies a number of characteristics of the servant-leader, such as listening, healing and stewardship. Another concept is that of "leading from behind" where leadership is provided but its source is unclear. Adaptive leadership (Heifetz, et al., 2009) pays close attention to a changing environment and distinguishes between technical problems (clear solution paths, often leaving underlying issues unresolved) and adaptive challenges (solutions requiring changes in people to achieve a longer lasting resolution).

Pedagogically, adaptive leadership means taking a constructivist approach to teaching and learning, moving away from the "sage on the stage" (King, 1993) and troubling the notion of "expert", a problematic mindset in the context of development work (Devereux, 2008). Classrooms instead become spaces for dialogue and knowledge construction with instructors as question-posing facilitators of discussions. Learners become subjects in their own learning (Vella, 2002).

\subsection{Ethical Community Engagement}

The technical mindset deliberately seeks to pre-empt any consideration of ethical issues, appealing largely to mathematical constructs. Mathematics is posited as objective and value-neutral. As the measure of engineering intellect, those working out of mathematical constructs (the "meat") assume that those actively engaged in ethical problems (the "fluff") have inferior mathematical skills (due to mutual exclusivity) and become targets of shame. Organizationally, hierarchies within the work environment allow engineers working at lower levels to pass their ethical responsibilities to the authoritative figure closer to the top. 
Ethical engagement, to achieve its full effect, cannot embrace the technical mindset. Ethical engagement seeks understanding and necessarily suppresses urges to create conformity. Bias is taken for granted. Its presence encourages us to recognize the importance of context and to wrestle with ambiguity. Mathematical constructs are human constructs and describe rather prescribe reality; as non-prescriptive, they cannot be used to constrain society. Indeed, the mathematization of engineering is itself the manifestation of a value. If "ordinary" engineers are to take ethical issues seriously as an integral part of engineering, they must move away from the hierarchical mindset and act according to their own convictions.

Ethical engagement is critical to CBEL pedagogy. Instructors draw heavily on the ethical principles and practices of community-based research in both the planning and delivery of the course. Principles include familiarity and sensitivity to communities, an emphasis on research being community-driven and the community partner's/members' needs taking precedence (Strand, et al., 2003; Minkler, 2004) and careful consideration given to research protocols and cultural differences (Ball and Janyst, 2008).

Ethics and ethical engagement are further framed as a "Reflexive Praxis", which suggests there is no one-size-fits-all, universal set of ethics: "Every decision requires weighing out circumstances, considering who is involved, what the costs and benefits might be, and mobilizing what we believe to be right into the decisions and actions that we take in any given moment" (EIESL Project, 2011). Students are continuously challenged to critically examine their own views, assumptions, convictions and actions, and to con-sider how power, functioning across social identities and creating dominant social systems, plays out in their projects. The new understandings are then brought to bear on the engineering discipline as a whole.

\subsection{Participatory Planning}

For the technical mindset, the stakeholders typically associated with participatory planning can be readily mapped to a pyramidal hierarchical structure. Engineers, with their specialized education and knowledge, see themselves at or near the top with the majority of the stakeholders closer to the bottom. The structure supports the "meat"/"fluff" dichotomy, placing greater importance on technical issues. Accommodating the needs of a wide range of stakeholders becomes "impractical"; concentrating on the technical assures a direct path from problem to solution.

If the needs and concerns of various stakeholders are to heard, understood and potentially acted upon, engineers need to temper the self-concept of "expert". Akin to the "honest broker" (Mitchell et al., 2004), "servant leadership" posits the engineer as a qualified person who can offer sound advice in the service of the communities affected by the proposed engineering project. Concerns may be challenged, but not summarily dismissed. The engineer is sensitive to issues of power and recognizes that participatory planning takes place within a political framework. Consensus is often not possible and trade-offs form a normal part of negotiation.

Within the classroom, students learn about participation by exploring what it means to actively engage and to move away from presumed hierarchical structures such as privileging academic knowledge over community knowledge. The greater pedagogical impact, however, is felt within community projects. As projects are developed from community partner priorities, community organizations fully participate in the project scoping. Students self-select projects based on interest; these projects are then further scoped, planned and carried out in close collaboration with community organizations and community members.

\subsection{Understanding Differences}

"Understanding differences" to the technical mindset means recognizing the differences so that they might be "fixed", for the "right answer" obsession equates difference with deficiency. The "right answer" is the one with the best technical performance as this best demonstrates the technical skills of the designer. Those thinking otherwise must be shown the error of their ways; attempts to accommodate difference are dismissed as impractical as they distract one from problem-to-solution path. 
In its non-technical form, "understanding differences" insists that there can be no single, right answer, for there are many ways of being, of living in the world. At the same time, the open mind must be tempered with knowledge and conviction to ensure that the engineering solution is not sidelined indefinitely in an effort to accommodate differences which ultimately have little impact. Differences create a break in the mundane and raise the possibility of the new. An attention to difference helps ensure that technology is in the service or people, not people in service of technology. Honest confrontation with difference, encourages self-re-examination, a critique of one's belief systems and a style of leadership that serves those in need.

APSC 461 intentionally forces students to understand and work across difference. It theoretically and pedagogically challenges ways of thinking and learning acquired through technical education. CBEL projects demand that students work across cultural and social differences among diverse communities. Guest speakers, readings and discussions address topics such as social identities, intercultural communication, and colonization and indigenous issues. Students examine their own assumptions and biases, actively seeking an understanding of how different cultural and social identities, worldviews, disciplines and paradigms lead to different approaches, and different ways of framing projects.

\section{COURSE RESTRUCTURING}

Restructuring of the course was carried out to better integrate the four key themes. A greater proportion of course material was delivered by the course instructor to ensure that the themes were explicitly covered. Guest speakers remained a crucial part of the course. Reflections, previously written in response to speaker presentations during class times, were reduced in number, and explicitly link the key themes to the CBEL projects. These reflections are written outside of class, thus freeing time for more inclass discussion. Many of these discussions are student-led, encouraging students to participate and to take an active role in their learning. Qualifying CBEL projects were carefully scoped to provide opportunities for students to encounter the four key themes in a real-life setting.

\section{STUDENT EXPERIENCES IN INTERNATIONAL SERVICE LEARNING (ISL): APSC 462}

APSC 462 is delivered through an international service learning experience where students build on the key themes introduced in APSC 461. The two-month placements are hosted by an agro-ecology centre in a rural community in southern Mexico. During these placements, students work on engineering-related projects that contribute to the organization's and surrounding community's longer term sustainable development goals. Past projects have included the design and building of a grey water filtration system, a solar water heater and design, redesign and construction of dry composting toilets to address local and regional water resource and sanitation priorities. Students musty also complete course assignments which include an extensive journal, three reflection papers (which build on the four themes of APSC 461), and a final paper reflecting on feedback from group members.

As part of an ISL program, APSC 462 students must meet the requirements of ISL in addition to those of the course. UBC's ISL programs focus on four broad categories of student learning outcomes: awareness of self and relations with others, global issues, change agency and educational impact. In addition, ISL students also pass through three "stages", participating in pre-departure sessions (which front-load learning themes and prepare students to work with community organizations), in-session workshops (facilitated by a staff member, students reflect on their experiences and draw connections to course and ISL concepts and themes), and a debrief workshop upon their return (where they reflect on the experience as a whole, make meaning of what they learned and how they can take it forward in their academic and personal lives).

The re-development of APSC 461 into the four themes has created greater synergies between the engineering aspects and the ISL components of the course, allowing for better integration of ISL projects and pedagogy. Though developed independently, the four themes of APSC 461 fit well with the four ISL learning outcomes categories. Being introduced within APSC 461, we believe these themes will better enable students to see their place as engineering students within the ISL learning outcome categories. 
Anecdotal evidence suggests that these four themes are in the right direction (no formal data is available). However, qualitative interview data from past (i.e., "pre-theme") ISL students support the anecdotal evidence. A five-year study looked at the level at which students demonstrated learning in each of the four ISL learning outcome categories. As the categories and themes were similar, reanalysis of the ISL data from an APSC 461/2 perspective became possible and showed that students had been struggling in APSC 462 with the same or similar concepts as we are now aiming to strengthen in APSC 461.

Understanding and working across difference was the theme most challenging for past students. This presented itself as challenges with cultural differences, practical differences, such as ways of working and construction methods, as well as conceptual differences around concepts such as sustainability. At a higher level there seemed to be less attention to power and privilege and how these operated within their projects, placements and on a broader social level:

"My biggest challenge was getting over the work ethic down there. It was pretty unorganized, the organization we worked with, and so we weren't able to efficiently do the work that we wanted to do. I guess, being there at the start and not really being completely comfortable and not really knowing your coordinator and stuff that well, we didn't really feel like pushing too much to get things done - just kind of sitting back and seeing how things are doing around there but how things are done around there is quite slow so that was the biggest challenge for me" (S09, post-experience interview).

A second and related challenge for students was participatory development. This also appeared in strong relation to the students' struggle with understanding and working across difference. There were many challenges to working collaboratively with local stakeholders in planning, designing and implementing projects. One student discusses the collaboration challenges between the student team, organization and a local community member:

"we were actually originally tasked with this retaining wall project by [Person X] and so we - that's very interesting - we kind of started this project at Organization A and we worked out of Organization A at our little makeshift office and we completed all our research there and then eventually established a contact with the construction guy who knew how to build these retaining walls out of tires and we completely disregarded any input from [Person Y] which, I guess - it's interesting why we didn't think of that but also why Organization A hadn't included him in the discussion of the project that was going on on his property. (S10, post-experience interview).

Lastly, when students were asked to reflect back on their experiences and how they linked them back to their discipline and course content, all engineering students in the study made clear connections to content and concepts in APSC 461. One student described these courses as "fundamental":

"the 461 - the pre-req -was -it kind of gave us an idea of a lot of concepts that tried to tie together development and engineering and also, like I said before, the traditional engineering curriculum is technical and it ignores the broader environment which we work in ... I think it should be mandatory for all engineers. I think that the themes that are echoed throughout 461 and illustrated in real life in 462 are so fundamental to engineering and how it should be taught" (S10, post-experience interview)

Student responses strongly indicate that APSC 461 is providing a conceptual framework for students to carry forward into the ISL experience of APSC 462. As more of the ISL analysis emerges, student experiences in APSC 462 will serve to create a dialectic relationship with APSC 461 facilitating the ongoing development of the two courses.

\section{CONCLUSION}

Informed by theoretical study and student feedback, we believe that the integration of the four key themes into the courses have better prepared students for work with local and global community partners. Formal studies in the future will allow us to better assess the impact of these themes on student preparedness; current informal feedback from partners suggests that preparedness has indeed improved. This will also help with further development and changes to course structure and content.

APSC 461/462 provides a wonderful opportunity to explore a wide range of themes in an engineering context, thanks to the support of administrative faculty and community-engaged learning staff (both local 
and international), as well as the offerings of a large university with its large student body and wealth of knowledgeable people to draw on. Success also depends on building and shepherding relationships with local and international community partners. Should similar models be replicated elsewhere, course designers would need to consider the time and resources required to support partnerships to ensure mutual understanding of expectations with appropriately scoped projects. Further considerations could include greater alignment with national or regional accreditation requirements.

\section{References}

Ball, J., and Janyst, P. 2008. Enacting Research Ethics in Partnerships with Indigenous Communities in Canada: 'Do it in a Good Way'. Journal of Empirical Research on Human Research Ethics, 3(2): 3351.

Cech, E.A. 2014. Education: Embed Social Awareness in Science Curricula. Nature, 505(7484): 477-8.

Centre for Community Engaged Learning. 2015. Retrieved from http://students.ubc.ca/about/centrecommunity-engaged-learning on February 13, 2015.

Croft, E., Winkelman, P., Boisvert, A. and Patten, K. 2013. Global Engineering Leadership - Design and Implementation of Local and International Service Learning Curriculum for Senior Engineering Students. Presented at the Canadian Engineering Education Association, Montreal, June.

Devereux, P. 2008. International Volunteering for Development and Sustainability: Outdated Paternalism or a Radical Response to Globalisation? Development in Practice, 18(3): 357-370.

EIESL Project. 2011. What is Ethics? Available at: http://ethicsofisl.ubc.ca/?page id=65.

Faulkner, W. 2000. Dualisms, Hierarchies and Gender in Engineering. Social Studies of Science, 30(5): 759-792.

Goss, K.A., Gastwirth, D.A. and Parkash, S.G. 2010. Research Service-Learning: Making the Academy Relevant Again. Journal of Political Science Education, 6(2): 117-141.

Heifetz, R.A., Linsky, M. and Grashow, A. 2009. The Practice of Adaptive Leadership. Cambridge Leadership Associates.

Kates, R.W., Clark, W.C., Corell, R., Hall, J.M., Jaeger, C.C., Lowe, I., McCarthy, J.J., et al. 2001. Sustainability Science. Science, 292: 641-642.

King, A. 1993. From Sage on the Stage to Guide on the Side. College Teaching: 41(1): 30-35.

Kronick, R. F., Cunningham, R. and Gourley, M. 2011. Experiencing Service-Learning. Univ. Ten Press.

Kuhn, Thomas 1970. The Structure of Scientific Revolutions. Chicago: The University of Chicago Press.

Lima, M. and Oakes, W. 2006. Service Learning: Engineering in Your Community. Oxford University Press.

Minkler M. 2004. Ethical challenges for the "outside" researcher in community based participatory research. Health Educ Behav. 31:684-701. doi: 10.1177/1090198104269566

Mirowski P. 2002. Machine Dreams: Economics Becomes a Cyborg Science. Cambridge: Cambridge University Press.

Mitchell, C.A., Carew, A.L. and Clift, R. 2004. The Role of the Professional Engineer and Scientist in Sustainable Development. In Aapagic, A., Perdan, S. and Clift, R. (eds.), Sustainable Development in Practice: Case Studies for Engineers and Scientists. Chichester: Wiley and Sons.

National Academy of Engineering. 2005. Educating the Engineer of 2020: Adapting Engineering Education to the New Century. Washington: The National Academies Press.

Nieusma, D. and Blue, E. 2012. Engineering and War. International Journal of Engineering, Social Justice, and Peace. 1(1): 50-62.

Spears, Larry C. 2004. Practicing Servant-Leadership. Leader to Leader. 34(Fall): 7-11.

Strand, K., Cutforth, N., Stoecker, R., Marullo, S. and Donohue, P. 2003. Community-based Research and Higher Education: Principles and Practices. San Francisco:Jossey-Bass.

Vella, J. K. 2002. Learning to Listen, Learning to Teach: The Power of Dialogue in Educating Adults. San Francisco, CA: Jossey-Bass.

Visser, M. 2002. Beyond Fate. Toronto: Anansi Press.

Wiek, A., Withycombe, L. and Redman, C. 2001. Key competencies in sustainability: a reference framework for academic program development. Sustainability Science, 6:203-218.

Canadian Engineering Accreditation Board. 2014. Accreditation Criteria and Procedures. Engineers Canada. 